\title{
A new trend on sustainable animal production
}

\author{
Liang Chou Hsia* \\ National Pingtung University of Science and Technology, Taiwan, ROC
}

\begin{abstract}
A sustainable animal production can improve the efficiency of animal production and recycle of animal waste, and reduce greenhouse gas emissions. It can be achieved by firstly, properly operation of animal production, such as improvement by animal breeding, synthesis of amino acids, improvement by animal nutrition, good housing design, phase feeding system, liquid feeding system, using left over of one day bakery and biscuit factory, left over of vegetable and fruit market, new methods to plant Leucaena or mulberry to feed goats, grass or fodder plant in hydroponic house for sustainable farming. Secondly, good waste management, such as transferring waste to no contaminant material and even to useful material, reduction of greenhouse gas emissions, liquid waste management, and solid waste treatment. All these subjects also need to consider the interaction between knowledge, e.g. breeding and nutrition need to consider about environmental temperature factors; waste management needs to consider about nutrient requirement by vegetable, fruit, etc. A sustainable animal production is a kind of science integrated different knowledge together, then you can achieve some good results.
\end{abstract}

\section{Introduction}

The operation of sustainable animal production tries to: (1) improve the efficiency of animal production and recycle of animal waste, consequently reduce waste produced from animal farms; (2) reduce waste material which cause and increase greenhouse effect of the world [1]. The improvement of efficiency on animal production not only reduces cost of animal production, but also reduces waste to soil and water. It is very important to reduce greenhouse gas which may destroy the world by the increasing of world environmental temperature.

\section{Basic principles}

The basic principles are, firstly, any method which can improve efficiency and reduce waste to soil, water, and air; secondly, any method which can treat waste efficiently and transfer them to become no contaminant to soil, water or air, or transfer them to become useful feed and fertilizer, etc.; thirdly, it is very important to reduce the production of greenhouse gas $[1,2]$.

\footnotetext{
* Corresponding author: 1chsia@mail.npust.edu.tw
} 


\section{How to achieve the above basic principles}

\subsection{Animal production part}

Feed efficiency $=$ Feed intake $/$ weight gain. If we can reduce the proportion of feed efficiency, then we can reduce waste in soil, water and air. Some of the most exciting examples can be seen in the animal production industry.

\subsubsection{Improvement by animal breeding}

Broiler is one of the best examples. During last 30-50 years, we can find the growth rate, feed intake and feed efficiency had fast improvement. The results cause better feed efficiency and increase weight gain. This means they waste less feed; that is, they achieve the goal of sustainable animal production.

\subsubsection{Synthesis of amino acids}

This is really a very important product in sustainable animal production because we may not easily make feed formulation. If we try to balance amino acids in diet, then it is not only more efficient to produce animal products but also reduce waste.

\subsubsection{Improvement by animal nutrition}

The following two ways are the best methods to improve feed efficiency and reduce waste of nutrient in animal production.

\subsubsection{Nutrient balance}

Nutrient balance contributes great improvement on growth rate and feed efficiency. This is due to balance nutrient can efficiently produce meat, eggs, and milk. They also can reduce waste. The most obvious example is the ideal protein concept. The concept is based on meat, eggs, and milk are constructed by specific amount of amino acids. If we can contribute specific amount of amino acids then it can synthesize specific amount of milk, meat or eggs. The result also can reduce the waste of nutrient, e.g. protein, energy and other nutrients [3].

\subsubsection{Growth promoter}

Antibiotics have been used as growth promoters for animals about 4-5 decades. Since people realize the resistant of bacteria to antibiotics, then the EU become the first area to ban the use of them. Now many Asia countries also ban on antibiotics. We have to thank to antibiotics during last years because they not only improve the efficiency of animal production, but also reduce the mortality during this period of time. This is one of great contribution by antibiotics. Today, we do not use antibiotics as growth promoters and replace by many new products, such as short chain fatty acids, medium chain fatty acids, essential oils, herbal medicine, etc. Some of these products not only can inhibit bacteria growth, but also can improve a great amount of growth performance. Some of them not only can kill bacteria, but also can inhibit virus, e.g. medium chain fatty acids and essential oils or herbal medicine. The good news is we do not use all these new growth promoters in human medicine, so there is no resistant problem. 


\subsubsection{Good housing design}

A good house design can improve the efficiency of animal production, e.g. good insulation of house can reduce heat and cold stress of animals. It also can reduce the waste of feeds with properly feeder design and enough feeding space.

\subsubsection{Phase feeding system}

Different stages of animals are provided different animal feeds which can reduce waste of feeds, especially the nitrogen loss of feeds. This system called phase feeding program (Fig. 1) [4].

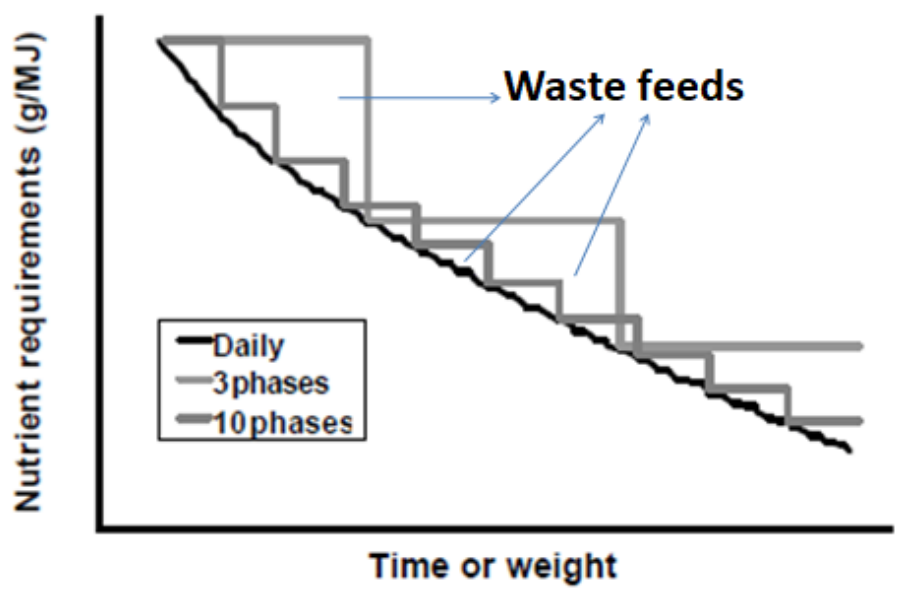

Fig. 1. Phase feeding

\subsubsection{Liquid feeding system}

This liquid feeding system is not only feeding animal by water + feed. The feeding system is combined feed with by-products of alcohol, cheese, juice, etc. industries.

\subsubsection{Left over of one day bakery and biscuit factory}

This part can be used for monogastric animals as an energy source. If we can help farmers to make a formula, then the farmers can use this cocked flour (bread and biscuit) to feed animals.

\subsubsection{Left over of vegetable and fruit market}

Most of the fresh left over can be fed to ruminant animals. It is good for them and they also enjoy to eat.

\subsubsection{New methods to plant Leucaena or mulberry to feed goats}

The goat is a kind of browsing animal. If we can plant mulberry or Leucaena in systematic way for them, then we can provide more nutritious feed for goats. 


\subsubsection{Grass or fodder plant in hydroponic house for sustainable farming}

This method is an advanced and sustainable way to plant grass or fodder for ruminants. It can save land, water, grass harvesting machine.

\subsection{Waste management}

\subsubsection{Sustainable animal production transfers waste to no contaminant material and even to useful material}

No contaminant by animal production is one way to keep clean of the world. To produce useful material is to make animal production even better from sustainable production point of view. There are two ways to make the decision which methods of animal waste treatment could select. The first method is to use water to wash animal waste and clean the pen. The wastewater is stored under the house or outside the house. The second method is to use scraper to clean waste and transfer to outside, then use it to make compost as a fertilizer. Figure 2 shows the flow chart of animal waste treatment and greenhouse gas production. The red characters $\left(\mathrm{CO}_{2}, \mathrm{CH}_{4}\right.$ and $\left.\mathrm{NH}_{3}\right)$ in the figure are greenhouse gas and ammonia.

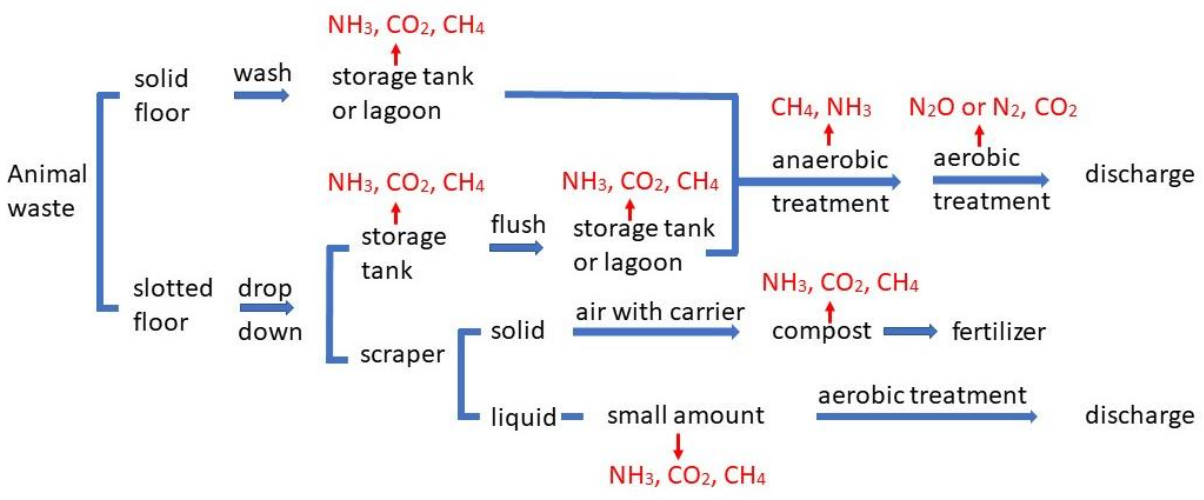

Fig. 2. Flow chart of animal waste treatment and greenhouse gas production

\subsubsection{Reduction of greenhouse gas emissions}

\subsubsection{The important greenhouse gas in animal production}

When farmers deal with animal waste, they should not only avoid smell but also need to avoid to produce greenhouse gas $\left(\mathrm{CO}_{2}, \mathrm{CH}_{4}, \mathrm{~N}_{2} \mathrm{O}\right)$ emissions in animal production area.

3.2.2.2 The most important waste treatment related to greenhouse gas and ammonia production in the treatment

Figure 3 shows the relationship between treatment methods and the situation which gas production. 


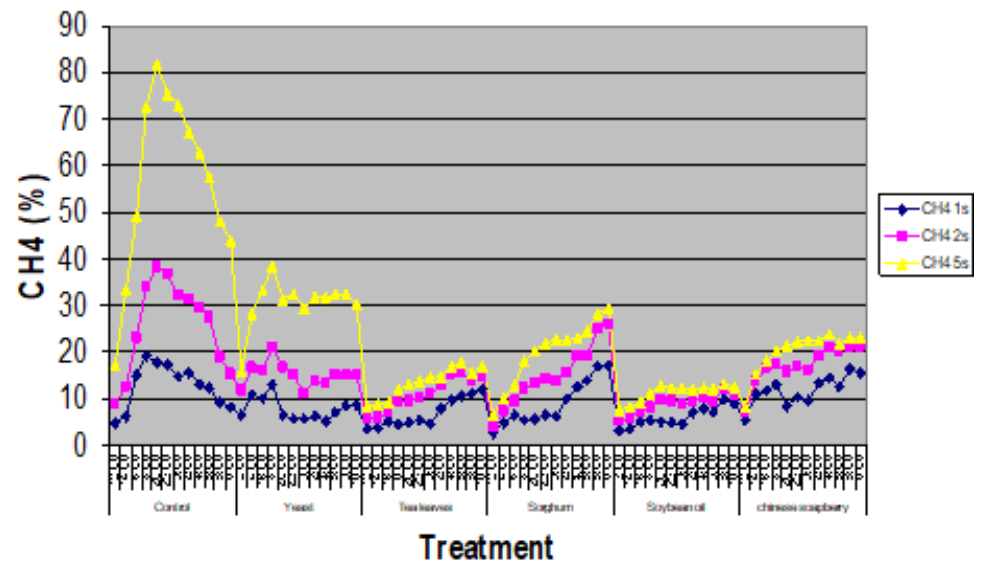

Fig. 3. Interaction between treatments and time on $\mathrm{CH}_{4}$ production $[5,6]$

\subsubsection{Liquid waste treatment}

The most significant point is to cover the anaerobic treatment and collect methane gas, let them not emit to air. This method also can avoid odor emission to air, then people can use methane as an energy source. It is important to use the heat produced by burning of methane gas to produce electricity. The heat can be used to heat the water which is used to produce algae. Because the algae water has large quantity, a little bit high temperature can let algae reproduce faster. The $\mathrm{CO}_{2}$ produced by methane burning also can introduce into pond. This can stimulate algae to reproduce even faster, due to photosynthesis in algae [7] needs $\mathrm{CO}_{2}$. Of course, the $\mathrm{CO}_{2}$ which produced by burning $\mathrm{CH}_{4}$ cannot easily consume by algae only. The algae are used to produce methane again, then the air can go into greenhouse and provide for vegetable growth. The purpose of all the procedure is to reduce greenhouse gas but also have positive effect to promote growth of vegetable.

\subsubsection{Solid waste treatment}

The second way to deal with animal waste is making compost which can be used for plant as a fertilizer. No matter which kinds of livestock or poultry, they need defecation and urination; that is, they cannot digest their food $100 \%$ and they have metabolism too. Both defecation and urination will discharge at least $20-40 \%$ of nutrient. The nutrient is also the nutrient required by plant, in consequence this is the good example of sustainable animal production. This method is also used by all ancestors since a thousand years ago.

\section{Conclusion}

A sustainable animal production is not only a simple subject but should be considered as a subject which related to many kinds of subjects on animal production, e.g. animal breeding, nutrition, management, housing, and waste management. All these subjects also need to consider the interaction between knowledge, e.g. breeding and nutrition need to consider about environmental temperature factors; waste management needs to consider about 
nutrient requirement by vegetable, fruit, etc. A sustainable animal production is a kind of science integrated different knowledge together, then you can achieve some good results.

\section{References}

1. L. C. Hsia., in Proceedings of the 2nd International Conference on Greenhouse Gases and Animal Agriculture GGAA2005-Working Papers, Institute of Animal Science, ETH-Zurich, Switzerland, Publication Series, 27, 286-289 (2005)

2. L. C. Hsia, in Proceedings of The 18th Asian-Australasian Animal Production Congress, Sarawak, Malaysia, p. 15 (2018)

3. R. A. Ballantyne, I. L. Hung, S. P. Su, Y. W. Chen, J. W. Lee, L. C. Hsia, in Proceedings of The 18th Asian-Australasian Animal Production Congress, Sarawak, Malaysia, p. 537 (2018)

4. L. A. den Hartog, G. B. C. Backus, J. A. M. Voermans, in Proceedings of Future of Pig Industry Conference, Pig Research Institute, Taiwan, pp. 51-61 (1991)

5. M. Moncada-Laínez, L. C. Hsia, in Proceedings of the 13th Animal Science Congress of the Asian-Australasian Association of Animal Production Societies, Hanoi, Vietnam, p. 94 (2008)

6. M. Moncada-Laínez, L. C. Hsia, Int. J. Anim. Veter. Adv. 8, 29-34 (2016)

7. N. Y. Chang, W. C. Kuo, L. C. Hsia, J. Chin. Soc. Anim. Sci. 38 (suppl.), 86 (2009) 